\title{
Rancang Bangun Sistem Pakar Diagnosa tingkat Depresi Pada Mahasiswa Tingkat Akhir Menggunakan Metode Fuzzy Tsukamoto(Studi Kasus : Universitas Siliwangi)
}

\author{
Neng Ika Kurniati ${ }^{1}$, Husni Mubarok ${ }^{2}$, Angga Reinaldi ${ }^{3}$ \\ Program Studi Teknik Informatika, Fakultas Teknik, Universitas Siliwangi \\ Jl. Siliwangi No. 24 Tasikmalaya 46115 \\ Telp. (0265) 330634 \\ Email : nengikakurniati@unsil.ac.id ${ }^{1}, \underline{\text { husnimubarok@unsil.ac.id }}{ }^{2}, \underline{\text { angga.reinaldi@ }}$ student.unsil.ac.id ${ }^{3}$
}

\section{ABSTRAK}

Depresi adalah penyakit mental yang umum tapi serius biasanya ditandai dengan perasaan sedih atau cemas. Kebanyakan mahasiswa kadang-kadang merasa sedih atau cemas, tapi emosi ini biasanya berlalu dengan cepat dalam beberapa hari. Depresi yang tidak diobati berlangsung untuk waktu yang lama, mengganggu kegiatan sehari-hari, dan jauh lebih dari sekedar "sedikit murung" atau "merasa sedih". Pada tahun 2011, Asosiasi Kesehatan American College National College Health Assessment (ACHANCHA) sebuah survei nasional pada mahasiswa di 2 dan 4 lembaga menemukan bahwa sekitar 30 persen dari mahasiswa melaporkan merasa "begitu tertekan sehingga sulit untuk berfungsi" pada beberapa waktu dalam satu tahun terakhir. Dengan dasar tersebut maka diperlukan sebuah sistem pakaruntuk membantu mahasiswa dalam mendeteksi tingkat depresi. Adapun sistem pakar yang dibuat dalam pembuatan sistem pakar ada tiga tahap utama dalam pengembangan software ini: fuzzifikasi, inferensi dan defuzzifikasi, menggunakan Tsukamoto pada tahap inference. Pada tahap defuzzifikasi, Center Average Deffuzzyfier digunakan untuk mendapatkan aturan outputcrisp.Basis Aturan yang digunakan dalam penelitian ini sebanyak 64 aturan. Adapun sistem pakar yang dibangun menggunakan metode Fuzzy Tsukamoto sebagai metode penalaran untuk menentukan hasil deteksi berdasarkan gejala yang ditunjukkan. Sistem pakar ini dibangun berbasis Desktop agar dapat digunakan oleh mahasiswa dan instansi/lembaga yang membutuhkan. Berdasarkanpengujian yang dilakukan, sistem pakar ini valid dengan tingkatakurasi sebesar 96\% dalam memberikan hasil deteksi yang sesuai dengan pakar, dari hasil data sebanyak 25 percobaan. Selain itu sistem dapat beroperasi baik. Kata kunci : Depresi, Sistem Pakar, Logika Fuzzy, Tsukamoto

\section{PENDAHULUAN}

Depresi merupakan gangguan kejiwaan pada alam perasaan (affective / mooddisorder) yang ditandai dengan gejala kemurungan, kelesuan, tidak ada gairah hidup, merasa tidak berguna, kekecewaan yang mendalam, rasa putus asa, pikiran kematian dan keinginan bunuh diri (Hawari, 2010).

Prevalensi depresi yang terjadi pada mahasiswa lebih tinggi dibandingkan populasi pada umumnya (Hariyanto, 2010). Pada Tahun 2009, American College Health Association - National College Health Assessment (ACHA - NCHA), pada dua dan empat lembaga menyatakan bahwa sekitar 30\% mahasiswa merasa depresi, sehingga sulit melakukan fungsi normalnya secara maksimal, hal ini menyimpulkan bahwa depresi mampu menurunkan performa dalam bidang akademik (National Institute of Mental Health, 2008).
Batasan masalah yang ada pada penelitian ini adalah Sistem pakar ini hanya membahas gejala - gejala depresi berdasarkan instrumen Beck Depression Inventory II (BDI II), Metode Fuzzy Tsukamoto digunakan untuk memperoleh rules dan mendiagnosatingkat depresi pada mahasiswa tingkat akhir, hasil output dari aplikasi adalah tingkat depresi yang melakukan diagnosa, Aplikasi sistem pakar ini berupa aplikasi berbasis Dekstop menggunakan Visual Basic .NET 2015 dan MySQL.

Tujuan dari penelitian ini adalah untuk merancang dan membangun suatu sistem pakar yang mampu memberikan diagnosa tingkat depresi pada mahasiswa tingkat akhir, dan mengimplementasikan Logika Fuzzy dengan metode Tsukamoto ke sistem pakar.Membantu dalam menentukan tingkat depresi mahasiswa tingkat akhir, yang di harapkan membantu untuk mengetahui tingkat depresi mahasiswa yang sedang mengambil skripsi/tugas akhir.

Manfaat yang dapat dihasilkan dari hasil penelitian ini adalah memberikan pengetahuan tentang gejala-gejala tingkat depresi pada mahasiswa tingkat akhir, diharapkan mampu membantu para mahasiswa melakukan penanganan secara dini mengenai depresi,dapat digunakan untuk mempermudah psikolog/konselor universitas yang menangani mahasiswa untuk memeriksa tingkat depresi.

\section{LANDASAN TEORI}

A. SISTEM PAKAR

Struktur sistem pakar terdiri dari dua pokok, yaitu lingkungan pengembang (development environment) dan lingkungan konsultasi (consulatation environment). Lingkungan pengembangan ini digunakan sebagai pembangunan sistem pakar baik dari segi pembangunan komponen maupun basis pengetahuan. Lingungan konsultasi digunakan oleh seorang bukan ahli untuk berkonsultasi. 


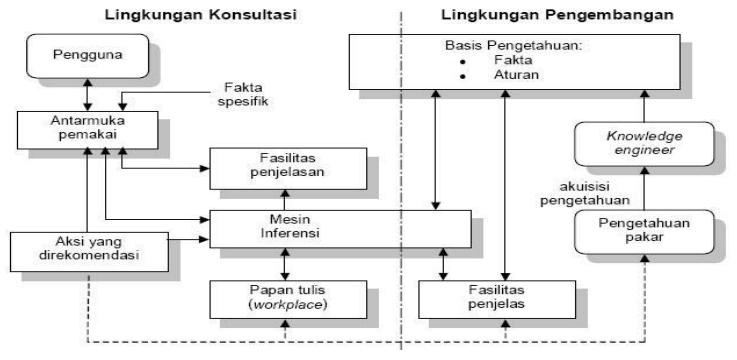

Gambar 1. Struktur Sistem Pakar

\section{B. FUZZY INFERENCE SYSTEM (FIS) METODE TSUKAMOTO}

Menurut Sri Kusumadewi dan Sri Hartati (2010:40) sistem inferensi fuzzy merupakan suatu kerangka komputasi yang didasarkan pada teori himpunan fuzzy, aturan fuzzy yang berbentuk IFTHEN, dan penalaran fuzzy.

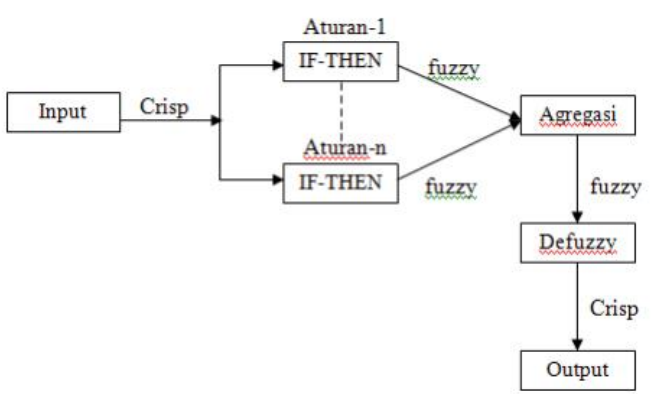

Gambar 2. Diagram Blok Sistem Inferensi Fuzzy

Sistem inferensi fuzzy menerima input crisp. Input ini kemudian dikirim ke basis pengetahuan yang berisi dan aturan fuzzy dalam bentuk IF-THEN. Fire strength (nilai keanggotaan anteseden atau $\alpha$ ) akan dicari pada setiap aturan. Apabila aturan lebih dari satu, maka akan dilakukan agregasi semua aturan. Selanjutnya pada hasil agregasi akan dilakukan defuzzy untuk mendapatkan nilai crisp sebagai output sistem.

Metode Tsukamoto adalah perluasan dari penalaran monoton. Pada metode Tsukamoto, setiap konsekuen pada aturan yang berbentuk IF-THEN harus direpresentasikan dengan suatu himpunan fuzzy dengan fungsi keanggotaan yang monoton. Sebagai hasilnya, output hasil inferensi dari tiap-tiap aturan diberikan secara tegas (crisp) berdasarkan apredikat (fire strength). Hasil akhirnya diperoleh dengan menggunakan rata-rata terbobot (Kusumadewi dan Hartati, 2010:31)
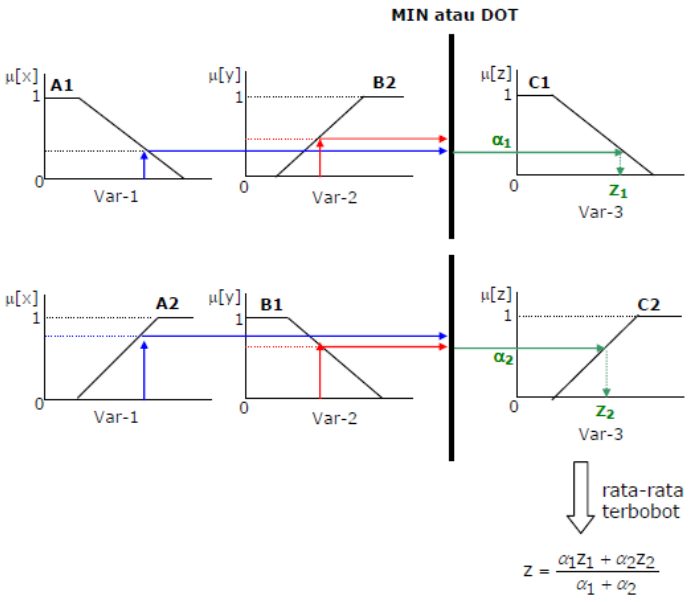

Gambar 3. Inferensi dengan menggunakan Metode Tsukamoto C. BECK DEPRESSION INVENTORY II (BDI II)

Beck Depression Inventory (BDI) adalah instrumen pengukuran tingkat depresi yang dibuat oleh Dr. Aaron T. Beck. BDI pertama kali diterbitkan pada tahun 1961 terdiri dari dua puluh satu pertanyaantentang bagaimana perasaan klien pada minggu terakhir terkait tanda dangejala depresi. BDI merupakan salah satu instrumen yang paling banyakdigunakan untuk mengukur tingkat keparahan depresi. Instrumen BDI dirancang untuk individu yang berusia 13 tahun dan lebih, dan terdiri dari pertanyaanyang berhubungan dengan gejala depresi seperti keputusasaan dan marah, kondisi seperti perasaan bersalah atau dihukum, serta gejala fisik sepertikelelahan, penurunan berat badan, dan kurangnya minat pada seks (Beck, 2006).

\section{METODOLOGI}

\section{A. METODOLOGI PENGEMBANGAN SISTEM}

Pengembangan sistem dapat diartikan sebagai sebuah proses pengembangan terstandarisasi yang mendefinisikan satu set aktivitas, metode, praktik terbaik, dan perangkat terotomatisasi yang akan digunakan oleh para pengembang sistem dan manjaer proyek untuk mengembangkan dan berkesinambungan memperbaiki sistem informasi dan perangkat lunak.

Dalam pengembangan sistem pakar ini, metodologi yang digunakan adalah Expert System Development Life Cyrcle (ESDLC) yang meliputi enam tahapan pokok.

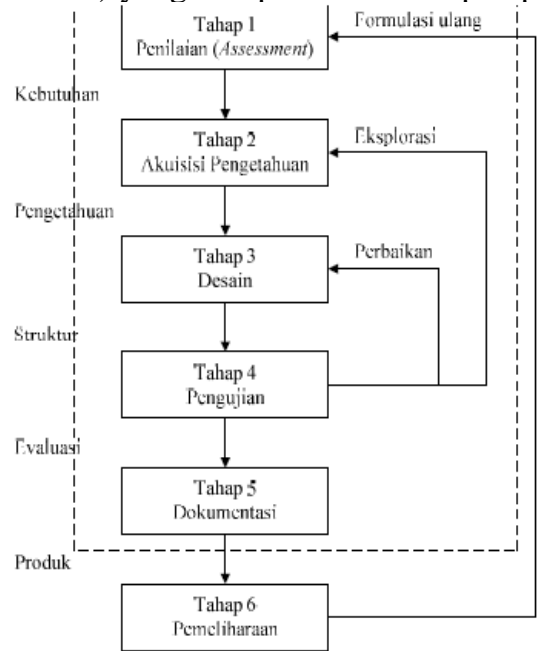

Gambar 4. Expert System Development Life Cycle

Alasan utama memilih metode pengembangan sistem ESDLC adalah metode pengembangan sistem ESDLC khusus untuk perancangan aplikasi sistem pakar. Alasan lainnya adalah pengembangan sistem pakar memiliki proses yang senantiasa berulang, setelah sistem dibangun dan diuji coba, proses tersebut akan terus berulang karena adanya tambahan pengetahuan baru. (Durkin, 1994).

\section{A. PEMBUATAN BASIS PENGETAHUAN}

Langkah yang dilakukan untuk membuat representasi pengetahuan berbentuk kaidah untuk basis pengetahuan sistem pakar ini adalah :

Tabel 1. Basis Pengetahuan

\begin{tabular}{|c|c|l|c|c|}
\hline Aturan & & \multicolumn{1}{|c|}{ Gejala } & $\begin{array}{c}\text { Tingkat } \\
\text { Depresi }\end{array}$ \\
\hline 1. & IF & $\begin{array}{l}\text { FKMinimal AND FAMinimal AND } \\
\text { FSMinimal }\end{array}$ & THEN & TDMINIMAL \\
\hline 2. & IF & $\begin{array}{l}\text { FKMinimal AND FAMinimal AND } \\
\text { FSRendah }\end{array}$ & THEN & TDMINIMAL \\
\hline 3. & IF & FKMinimal AND FAMinimal AND & THEN & TDMINIMAL \\
\hline
\end{tabular}




\begin{tabular}{|c|c|c|c|c|}
\hline & & FSSedang & & \\
\hline 4. & $\mathrm{IF}$ & FKMinimal AND FAMinimal AND FSBerat & THEN & TDRENDAH \\
\hline 5 & $\mathrm{IF}$ & $\begin{array}{l}\text { FKMinimal AND FARendah AND } \\
\text { FSMinimal }\end{array}$ & THEN & TDMINIMAL \\
\hline 6 & IF & $\begin{array}{l}\text { FKMinimal AND FARendah AND } \\
\text { FSRendah }\end{array}$ & THEN & TDMINIMAL \\
\hline 7 & IF & $\begin{array}{l}\text { FKMinimal AND FARendah AND } \\
\text { FSSedang }\end{array}$ & THEN & TDRENDAH \\
\hline 8 & IF & FKMinimal AND FARendah AND FSBerat & THEN & TDRENDAH \\
\hline 9 & $\mathrm{IF}$ & $\begin{array}{l}\text { FKMinimal AND FASedang AND } \\
\text { FSMinimal }\end{array}$ & THEN & TDRENDAH \\
\hline 10 & IF & $\begin{array}{l}\text { FKMinimal AND FASedang AND } \\
\text { FSRendah }\end{array}$ & THEN & TDSEDANG \\
\hline 11 & IF & $\begin{array}{l}\text { FKMinimal AND FASedang AND } \\
\text { FSSedang }\end{array}$ & THEN & TDSEDANG \\
\hline 12 & $\mathrm{IF}$ & FKMinimal AND FASedang AND FSBerat & THEN & TDSEDANG \\
\hline 13 & $\mathrm{IF}$ & FKMinimal AND FABerat AND FSMinimal & THEN & TDSEDANG \\
\hline 14 & $\mathrm{IF}$ & FKMinimal AND FABerat AND FSRendah & THEN & TDSEDANG \\
\hline 15 & IF & FKMinimal AND FABerat AND FSSedang & THEN & TDBERAT \\
\hline 16 & IF & FKMinimal AND FABerat AND FSBerat & THEN & TDBERAT \\
\hline 17 & IF & $\begin{array}{l}\text { FKRendah AND FAMinimal AND } \\
\text { FSMinimal }\end{array}$ & THEN & TDMINIMAL \\
\hline 18 & IF & $\begin{array}{l}\text { FKRendah AND FAMinimal AND } \\
\text { FSRendah }\end{array}$ & THEN & TDRENDAH \\
\hline 19 & IF & $\begin{array}{l}\text { FKRendah AND FAMinimal AND } \\
\text { FSSedang }\end{array}$ & THEN & TDRENDAH \\
\hline 20 & IF & FKRendah AND FAMinimal AND FSBerat & THEN & TDSEDANG \\
\hline 21 & $\mathrm{IF}$ & $\begin{array}{l}\text { FKRendah AND FARendah AND } \\
\text { FSMinimal }\end{array}$ & THEN & TDMINIMAL \\
\hline 22 & IF & FKRendah AND FARendah AND FSRendah & THEN & TDRENDAH \\
\hline 23 & $\mathrm{IF}$ & FKRendah AND FARendah AND FSSedang & THEN & TDSEDANG \\
\hline 24 & $\mathrm{IF}$ & FKRendah AND FARendah AND FSBerat & THEN & TDSEDANG \\
\hline 25 & $\overline{\mathrm{IF}}$ & $\begin{array}{l}\text { FKRendah AND FASedang AND } \\
\text { FSMinimal } \\
\end{array}$ & THEN & TDRENDAH \\
\hline 26 & $\mathrm{IF}$ & FKRendah AND FASedang AND FSRendah & THEN & TDSEDANG \\
\hline 27 & IF & FKRendah AND FASedang AND FSSedang & THEN & TDSEDANG \\
\hline 28 & IF & FKRendah AND FASedang AND FSBerat & THEN & TDBERAT \\
\hline 29 & IF & FKRendah AND FABerat AND FSMinimal & THEN & TDSEDANG \\
\hline 30 & $\mathrm{IF}$ & FKRendah AND FABerat AND FSRendah & THEN & TDSEDANG \\
\hline 31 & IF & FKRendah AND FABerat AND FSSedang & THEN & TDSEDANG \\
\hline 32 & IF & FKRendah AND FABerat AND FSBerat & THEN & TDBERAT \\
\hline 33 & $\mathrm{IF}$ & $\begin{array}{l}\text { FKSedang AND FAMinimal AND } \\
\text { FSMinimal }\end{array}$ & THEN & TDSEDANG \\
\hline 34 & IF & $\begin{array}{l}\text { FKSedang AND FAMinimal AND } \\
\text { FSRendah }\end{array}$ & THEN & TDSEDANG \\
\hline 35 & IF & $\begin{array}{l}\text { FKSedang AND FAMinimal AND } \\
\text { FSSedang }\end{array}$ & THEN & TDBERAT \\
\hline 36 & IF & FKSedang AND FAMinimal AND FSBerat & THEN & TDBERAT \\
\hline 37 & $\mathrm{IF}$ & $\begin{array}{l}\text { FKSedang AND FARendah AND } \\
\text { FSMinimal }\end{array}$ & THEN & TDSEDANG \\
\hline 38 & IF & FKSedang AND FARendah AND FSRendah & THEN & TDSEDANG \\
\hline 39 & IF & FKSedang AND FARendah AND FSSedang & THEN & TDBERAT \\
\hline 40 & $\mathrm{IF}$ & FKSedang AND FARendah AND FSBerat & THEN & TDBERAT \\
\hline 41 & $\mathrm{IF}$ & $\begin{array}{l}\text { FKSedang AND FASedang AND } \\
\text { FSMinimal }\end{array}$ & THEN & TDBERAT \\
\hline 42 & $\mathrm{IF}$ & FKSedang AND FASedang AND FSRendah & THEN & TDBERAT \\
\hline 43 & IF & FKSedang AND FASedang AND FSSedang & THEN & TDBERAT \\
\hline 44 & $\mathrm{IF}$ & FKSedang AND FASedang AND FSBerat & THEN & TDBERAT \\
\hline 45 & IF & FKSedang AND FABerat AND FSMinimal & THEN & TDBERAT \\
\hline 46 & $\mathrm{IF}$ & FKSedang AND FABerat AND FSRendah & THEN & TDBERAT \\
\hline 47 & $\mathrm{IF}$ & FKSedang AND FABerat AND FSSedang & THEN & TDBERAT \\
\hline 48 & IF & FKSedang AND FABerat AND FSBerat & THEN & TDBERAT \\
\hline 49 & $\mathrm{IF}$ & $\begin{array}{l}\text { FKBerat AND FAMinimal AND } \\
\text { FSMinimal }\end{array}$ & THEN & TDBERAT \\
\hline 50 & IF & FKBerat AND FAMinimal AND FSRendah & THEN & TDBERAT \\
\hline 51 & $\mathrm{IF}$ & FKBerat AND FAMinimal AND FSSedang & THEN & TDBERAT \\
\hline 52 & $\mathrm{IF}$ & FKBerat AND FAMinimal AND FSBerat & THEN & TDBERAT \\
\hline 53 & $\mathrm{IF}$ & FKBerat AND FARendah AND FSMinimal & THEN & TDBERAT \\
\hline 54 & IF & FKBerat AND FARendah AND FSRendah & THEN & TDBERAT \\
\hline 55 & $\mathrm{IF}$ & FKBerat AND FARendah AND FSSedang & THEN & TDBERAT \\
\hline 56 & IF & FKBerat AND FARendah AND FSBerat & THEN & TDBERAT \\
\hline 57 & IF & FKBerat AND FASedang AND FSMinimal & THEN & TDBERAT \\
\hline 58 & $\mathrm{IF}$ & FKBerat AND FASedang AND FSRendah & THEN & TDBERAT \\
\hline 59 & $\mathrm{IF}$ & FKBerat AND FASedang AND FSSedang & THEN & TDBERAT \\
\hline 60 & $\mathrm{IF}$ & FKBerat AND FASedang AND FSBerat & THEN & TDBERAT \\
\hline 61 & $\mathrm{IF}$ & FKBerat AND FABerat AND FSMinimal & THEN & TDBERAT \\
\hline 62 & IF & FKBerat AND FABerat AND FSRendah & THEN & TDBERAT \\
\hline 63 & IF & FKBerat AND FABerat AND FSSedang & THEN & TDBERAT \\
\hline 64 & $\mathrm{IF}$ & FKBerat AND FABerat AND FSBerat & THEN & TDBERAT \\
\hline
\end{tabular}

\section{B. DESIGN}

Setelah setiap indikator serta gejala klinis diformulasikan secara lengkap,kemudian diimplementasikan dengan membuat perancangan sistem yang akan dibangun.Perancangan sistem ini terdiri atas perancangan sistem, perancangan database, dan perancangan antarmuka pemakai (User interface). Dalam perancangan sistem pakar diagnosa tingkatdepresi pada mahasiswa tingkat akhir dengan metode tsukamoto, meliputi:

1. Perancangan Flowchart

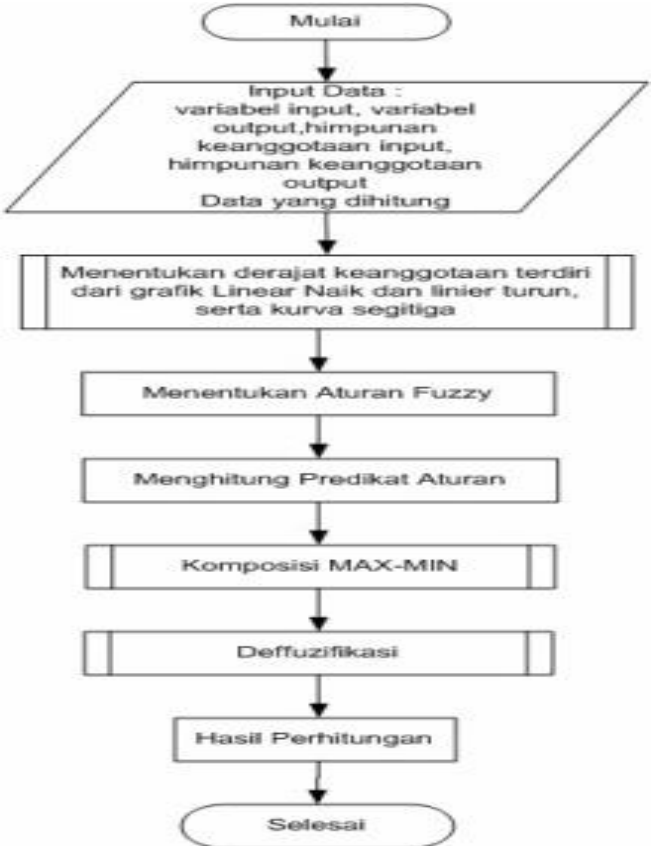

Gambar 5. Flowchart Logika Fuzzy

\section{Perancangan Database}

Entity Relationship Diagram (ERD) merupakan suatu model untuk menjelaskan hubungan antar data dalam basis data berdasarkan objek-objek dasar data yang mempunyai hubungan antar relasi. ERD untuk memodelkan struktur data dan hubungan antar data, untuk menggambarkannya digunakan beberapa notasi dan symbol.

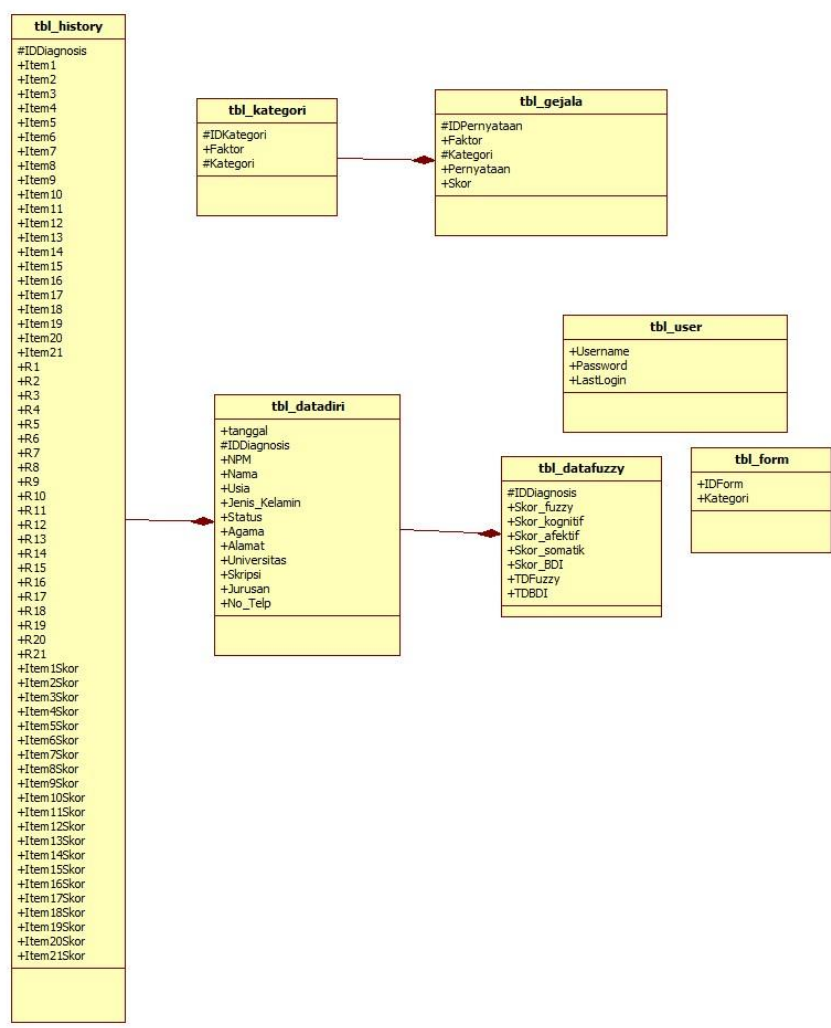

Gambar 6. Entity Relationship Diagram 
3. Perancangan UML

a. Use Case Diagram

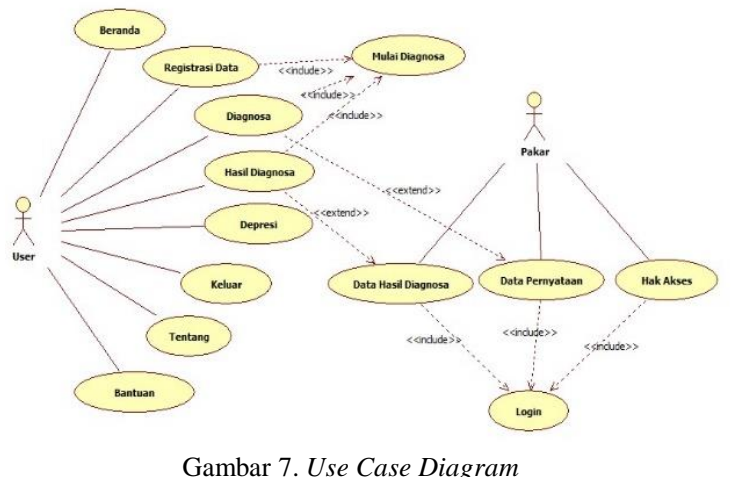

IV. HASIL DAN PEMBAHASAN

\section{A. IMPLEMENTASI SISTEM}

Tahapan ini merupakan tahapan dimana hasil dari perancangan antarmuka yang telah diimplementasikan kedalam program yang dibuat dengan menggunakan bahasa pemrograman Visual Basic .NET dan basis data yang digunakan adalah MySQ1.

1. Form Beranda

Form Beranda ini merupakan tampilan awal dari aplikasi, pada tahap ini terdapat pilihan untuk mengakses menu 'Mulai Diagnosa', 'Beranda', 'Login', 'Pengetahuan Depresi', dan 'Keluar'.

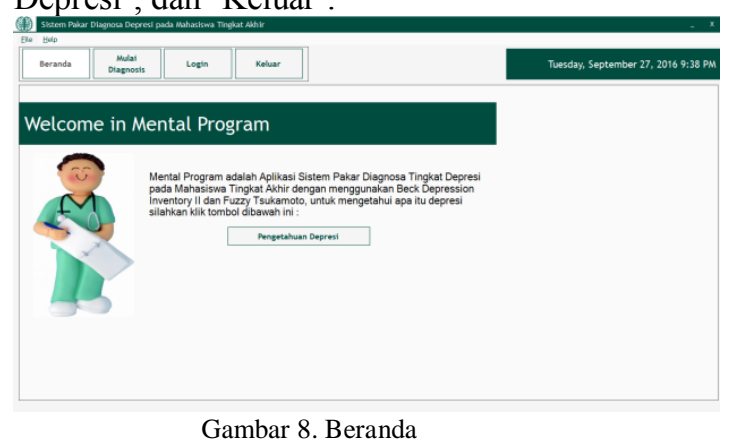

\section{Form Diagnosa}

Pada form ini pengguna menjawab semua pernyataan yang berjumlah 21 pernyataan yang terbagi dalam 3 faktor, yaitu factor kognitif, afektif dan somatik.

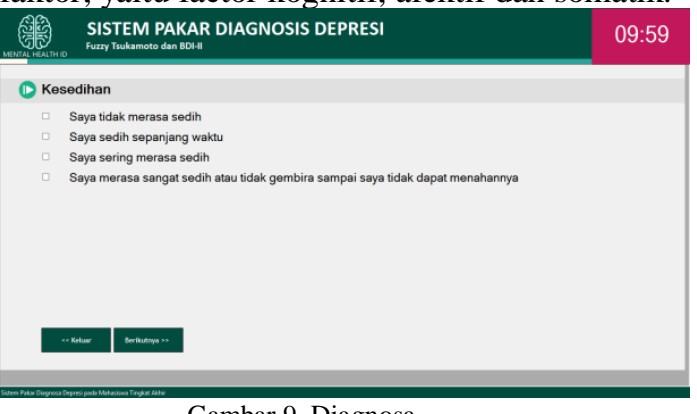

$$
\text { Gambar 9. Diagnosa }
$$

\section{B. PENGUJIAN SISTEM}

Pengujian sistem dimaksudkan untuk menguji semua elemen-elemen pada aplikasi yang telah dibuat apakah sudah selesai dengan yang diharapkan. Pengujian elemenelemen perintah dalam kerja praktek ini dilaksanakan oleh pihak user atau pengguna.

\section{PENGUJIAN AKURASI}

Analisis Perhitungan Metode menjelaskan perhitungan tingkat depresi menggunakan Fuzzy Tsukamoto.
Sebelumnya telah dilakukan penyebaran instrumen BDI kepada 25 mahasiswaUniversitas Siliwangi Tasikmalaya sebagai objek penelitian. Dan dari hasil penyebaran instrument tersebut diperoleh data berikut

\begin{tabular}{|c|c|c|c|c|c|}
\hline \multirow{2}{*}{ No } & \multirow{2}{*}{ Nama Mahasiswa } & \multicolumn{2}{|c|}{ Total Skor } & \multicolumn{2}{|c|}{ Tingkat Depresi } \\
\hline & & BDI & Fuzzy & BDI & Fuzzy \\
\hline 1 & Faizal Rifki Suandi & 14 & 13.377 & Ringan & Ringan \\
\hline 2 & Zaki Mubarok & 24 & 25.278 & Sedang & Sedang \\
\hline 3 & Mohammad Fahrurrazi & 23 & 21.343 & Sedang & Sedang \\
\hline 4 & Mohamad Ikhsan Karis & 11 & 10.909 & Minimal & Minimal \\
\hline 5 & Taufiq Nurrohman & 24 & 23.831 & Sedang & Sedang \\
\hline 6 & Irfan Alfian Febrianto & 12 & 12.032 & Minimal & Minimal \\
\hline 7 & Iqbal Fauzy Ginanjar & 22 & 22.791 & Sedang & Sedang \\
\hline 8 & Panji Wijaksono & 16 & 17.204 & Ringan & Ringan \\
\hline 9 & Hafidz Jaelani & 22 & 24.398 & & Sedang \\
\hline 10 & Salas Ri & 23 & 22.567 & ang & Sedang \\
\hline 11 & Asep Henc & 32 & 28.333 & & Berat \\
\hline 12 & $\begin{array}{l}\text { Tiansyah Fajar } \\
\text { Ramdhani }\end{array}$ & 4 & 7.306 & Minimal & Minimal \\
\hline 13 & Joni Alexander & 8 & 10.469 & Minimal & Minimal \\
\hline 14 & Ryan & 19 & 17.392 & Ringan & Ringa \\
\hline 15 & Fitri Ran & 13 & 12.186 & Minimal & Minimal \\
\hline 16 & Irfan Rar & 29 & 29.567 & Berat & Berat \\
\hline 17 & A Faisal Rahma & 24 & 21.265 & Sedang & Sedang \\
\hline 18 & $\begin{array}{l}\text { Risye Yusriah } \\
\text { Wulansari }\end{array}$ & 17 & 16.946 & Ringan & Ringan \\
\hline 19 & Suci Denistina & 20 & 19.563 & Sedang & Sedang \\
\hline 20 & Eva Nurjanah & 20 & 19.155 & Sedang & Sedang \\
\hline 21 & Astri Ayu Wahyuni & 27 & 26.477 & Sedang & Sedang \\
\hline 22 & Anis Maspupah & 18 & 17.386 & Ringan & Ringan \\
\hline 23 & Ade & 21 & 16.500 & Sedang & Ringan \\
\hline 24 & Angga Reinaldi & 29 & 28.372 & Berat & Berat \\
\hline 25 & Tito Iwaldo Anugerah & 26 & 24.884 & Sedang & Sedang \\
\hline
\end{tabular}

Dari data-data tersebut diambil satu objek penelitian sebagai kasus pada analisis perhitungan metode Fuzzy Tsukamoto. Misalkan kasus yang diambil adalah data dari Faizal Rifky Suandi dengan skor Faktor Kognitif : 5,Faktor Afektif : 4 dan Faktor Somatik: 5.

Representasi Faktor Kognitif

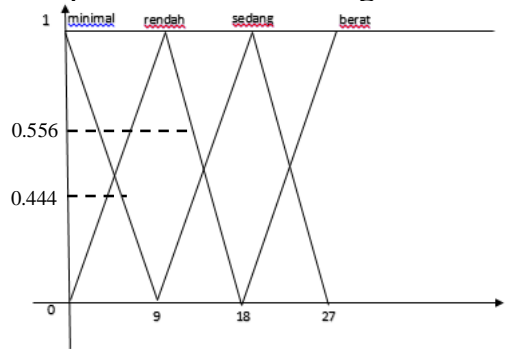

Fungsi Keanggotaan :

$$
\begin{aligned}
& \mu \mathrm{FKminimal}[\mathrm{x}]= \begin{cases}\frac{(9-5) ;}{9} & 0 \leq 5 \leq 9 \\
0 ; & 5 \geq 9\end{cases} \\
& \text { Dengan nilai keanggotan } \mu \mathrm{FKminimal} \\
& \mu \text { FKMininmal }\left[{ }^{[5]}=0,444 ; \ldots \ldots .(1)\right. \\
& \mu \mathrm{FKrendah}[\mathrm{x}]=\left\{\begin{array}{cl}
0 ; & 5 \leq 0 \text { atau } 5 \geq 18 \\
\frac{(5-0) ;}{9} & 0 \leq 5 \leq 9 \\
\frac{(9-5) ;}{9} & 9 \leq 5 \leq 18
\end{array}\right. \\
& \text { Dengan nilai keanggotan } \mu \mathrm{FKrendah} \\
& \mu \mathrm{FKrendah}{ }^{[5]}=(5-0) / 9 \\
& =0,556 ; \ldots \ldots \ldots \ldots .(2) \\
& \mu \mathrm{FK} \text { sedang }[x]=\left\{\begin{array}{cl}
0 ; & 5 \leq 0 \text { atau } 5 \geq 18 \\
\frac{(5-9) ;}{9} & 9 \leq 5 \leq 27 \\
\frac{(27-5) ;}{9} & 18 \leq 5 \leq 27
\end{array}\right. \\
& \mu \mathrm{FKberat}{ }^{[x]}=\left\{\begin{array}{cl}
0 ; & 5 \leq 18 \\
\frac{(5-18) ;}{9} & 18 \leq 5 \leq 27 \\
1 & 5 \geq 27
\end{array}\right.
\end{aligned}
$$


Representasi Faktor Afektif

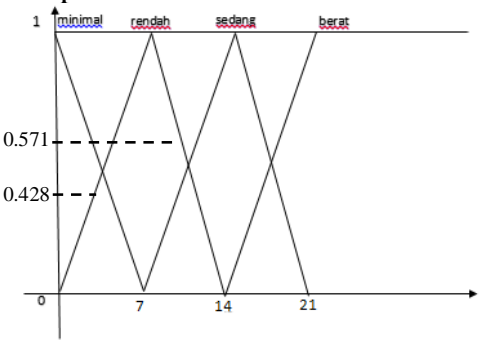

Fungsi Keanggotaan :

$\mu \mathrm{FAminimal}^{[\mathrm{x}]}=\left\{\begin{array}{c}\frac{(9-4) ;}{7} 0 \leq 5 \leq 7 \\ 0 ; \quad 5 \geq 7\end{array}\right.$

$\mu \mathrm{FArendah}[\mathrm{x}]=\left\{\begin{array}{cl}0 ; & 4 \leq 0 \text { atau } 4 \geq 14 \\ \frac{(4-0) ;}{7} & 0 \leq 4 \leq 7 \\ \frac{(7-4) ;}{7} & 7 \leq 4 \leq 14\end{array}\right.$

$\mu$ FAsedang $[x]= \begin{cases}0 ; & 4 \leq 0 \text { atau } 4 \geq 14 \\ \frac{(4-7) ;}{7} & 7 \leq 4 \leq 21 \\ \frac{(21-4) ;}{7} & 14 \leq 4 \leq 21\end{cases}$

$\mu$ FAberat $^{[\mathrm{x}]}=\left\{\begin{array}{cl}0 ; & 4 \leq 14 \\ \frac{(4-14) ;}{7} & 14 \leq 4 \leq 21 \\ 1 & 4 \geq 21\end{array}\right.$

Representasi Faktor Somatik

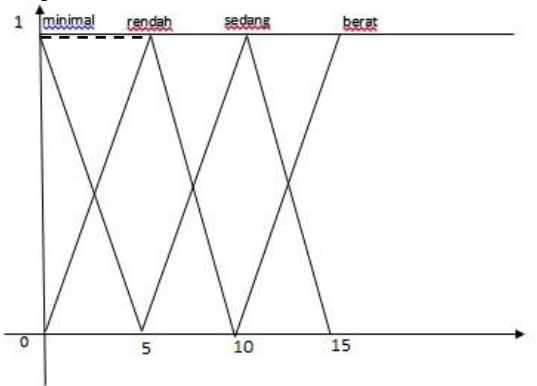

Fungsi Keanggotaan :

$\mu \mathrm{FSminimal}[\mathrm{x}]=\left\{\begin{array}{cc}\frac{(5-5) ;}{5} & 0 \leq 5 \leq 5 \\ 0 ; & 5 \geq 5\end{array}\right.$

$\mu$ FSrendah $[x]=\left\{\begin{array}{cl}0 ; & 5 \leq 0 \text { atau } 5 \geq 10 \\ \frac{(5-0) ;}{5} & 0 \leq 5 \leq 5 \\ \frac{(5-5) ;}{5} & 5 \leq 5 \leq 10\end{array}\right.$

$\mu \mathrm{FSsedang}^{[\mathrm{x}]}=\left\{\begin{array}{cl}0 ; & 5 \leq 0 \text { atau } 5 \geq 15 \\ \frac{(5-5) ;}{5} & 5 \leq 5 \leq 15 \\ \frac{(15-5) ;}{5} & 10 \leq 5 \leq 15\end{array}\right.$

$\mu$ FSberat $[x]=\left\{\begin{array}{cl}0 ; & 5 \leq 10 \\ \frac{(5-10) ;}{5} & 10 \leq 5 \leq 15 \\ 1 & 4 \geq 15\end{array}\right.$
Representasi Tingkat Depresi

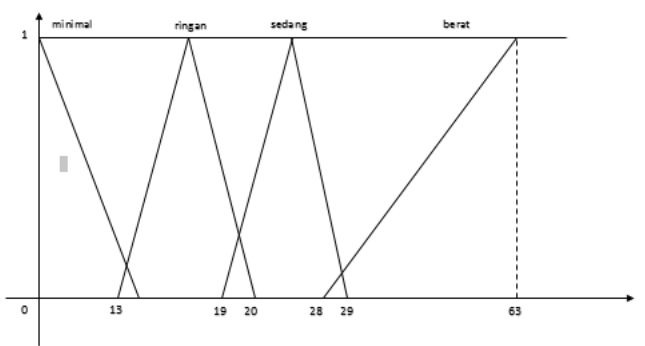

Dengan nilai keanggotan $\mu$ FAminim

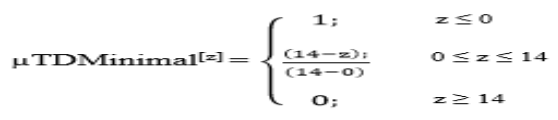

$\mu$ FAminimal ${ }^{[4]}=0,428$;

(5)

Dengan nilai keanggotan $\mu$ FArendal

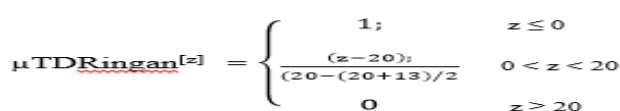

$\mu \mathrm{FArendah}^{[4]}=(4-0) / 7$

$=0,571 ;$

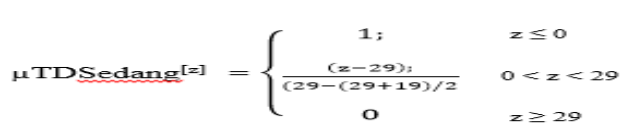

Dengan nilai keanggotaan $\mu \mathrm{FAsedat}$

uTDBerat $[z]$

$z \leq 0$

$z \geq 29$

$u$ FAsedang $\left[{ }^{[4]}=0 ; \ldots \ldots \ldots \ldots\right.$ (7)

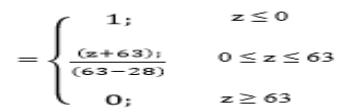

64 aturan tersebut kemudian dimasukan ke dalam mesin inferensi. Pada mesin inferensi, diterapkan Dengan nilai keanggotan $\mu$ FAberat fungsi MIN untuk setiap aturan pada aplikasi fungsi $\mu$ FAberat ${ }^{[4]}=0 ; \ldots \ldots \ldots . . .(8)$ implikasinya. Dan dari kasus diatas maka aturan yang digunakan adalah sebagai berikut:

$\begin{array}{llll}\text { [R2] } & \text { IF FKMinimal AND FAMinimal AND FSRendah } & \text { THEN } & \text { TDMINIMAL } \\ {[\text { R6] }} & \text { IF FKMinimal AND FARendah AND FSRendah } & \text { THEN } & \text { TDMINIMAL }\end{array}$

$\begin{array}{llll}{[\text { R6] }} & \text { IF FKMinimal AND FARendah AND FSRendah } & \text { THEN } & \text { TDMINIMAL } \\ {[\text { R18] }} & \text { IF FKRendah AND FAMinimal AND FSRendah } & \text { THEN } & \text { TDRENDAH }\end{array}$

$\begin{array}{llll}\text { [R18] } & \text { IF FKRendah AND FAMinimal AND FSRendah } & \text { THEN } & \text { TDRENDAH } \\ \text { [R22] } & \text { IF FKRendah AND FARendah AND FSRendah } & \text { THEN } & \text { TDRENDAH }\end{array}$

[R2] IF FKMinimal AND FAMinimal AND FSRendah then TDminimal;

$\alpha$ - predikat $_{1}=\mu$ FKMinimal $\cap$ FAMinimal $\cap$ FSRendah

$=\operatorname{MIN}(F K M i n i m a l[0.444] \cap$ FAMinimal $[0.428] \cap$ FSRendah

[1])

$=\operatorname{MIN}(0.444 ; 0.428 ; 1)$

$=0.428$

Lihat himpunan TDminimal pada representasi grafik variabel tingkat depresi

$(14-z) /(14-0)=0.428 \cdots, z_{2}=8.008$

[R6] IF FKMinimal AND FARendah AND FSRendah then TDrendah.

Dengan nilai keanggotan $\mu \mathrm{FSminin}$

$\mu \mathrm{FSminimal}[5]=0 ; \ldots . . .(9)$

$=\operatorname{MIN}(\mu \mathrm{FKMinimal}[0.444] \cap \mu$ FARendah [0.571] $\cap$

Dengan nilai keanggotan $\mu$ FSrendal $\quad=\operatorname{MIN}(0.444 ; 0.571 ; 1)$

$\mu \mathrm{FSrendah}\left[{ }^{[5]}=(5-0) / 6\right.$

$=0.444$

$$
=1
$$

Lihat himpunan TDminimal pada representasi grafik variabel tingkat depresi

$$
(14-\mathrm{z}) /(14-0)=0.444 \rightarrow \quad \mathrm{z} 6=7.784
$$

[R18] IF FKRendah AND FAMinimal AND FSRendah then TDrendah:

Dengan nilai keanggotaan $\mu \mathrm{FS}$ sedat

$\mu \mathrm{FS}$ sedang ${ }^{[5]}=0$;

$=\operatorname{MIN}(\mu \mathrm{FKR}$ Rendah $[0.556] \cap \mu \mathrm{FAMinimal} \quad[0.428] \cap$

$\mu$ FSRendah [1])

$=\operatorname{MIN}(0.556 ; 0.428 ; 1)$

$=0.428$

Dengan nilai keanggotan $\mu \mathrm{FS}$ berat ${ }^{L}$ ihat himpunan $\mathrm{TD}$ rendah pada representasi grafik variabel tingkat depresi

$\mu \mu \mathrm{FSberat}{ }^{[3]}=0 ; \ldots \ldots \ldots \ldots(12)$ $(z-20): / 20-(13+20) / 2=0.428 \ldots \ldots \rightarrow \quad z 18=18.502$ 
[R22] IF FKRendah AND FARendah AND FSRendah then TDRendah:

$\alpha$-predikat $4=\mu$ FKRendah $\cap \mu$ FARendah $\cap \mu$ FSRendah

$=\operatorname{MIN}(\mu \mathrm{FKrendah}[0.556] \cap \mu \mathrm{FArendah}[0.571] \cap \mu \mathrm{FSrendah}[1])$

$=\operatorname{MIN}(0.556 ; 0.444 ; 1)$

$=0.444$

Lihat himpunan TDrendah pada representasi grafik variabel tingkat depresi

$$
(z-20) ; / 20-(13+20) / 2=0.556 \ldots \ldots \quad z_{22}=18.04
$$

Setelah diperoleh $\alpha$-predikatdan $\mathrm{z}$ pada setiap rule, maka tahap terakhir adalah defuzzyfikasi. Nilai tegas (crisp) $\mathrm{z}$ dapat dicari menggunakan rata - rata terbobot, yaitu:

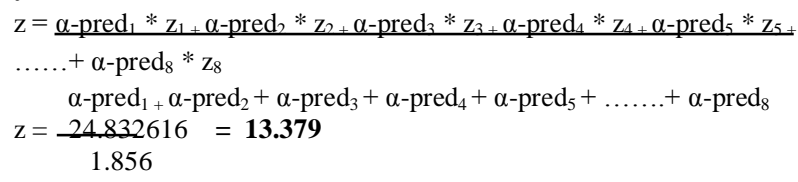

Hasilnya, diperoleh angka 13.379 pada tahap defuzzyfikasi dimana angka tersebut berada pada interval Tingkat Depresi Ringan. Dengan demikian hasil diagnosis dari kasus Faizal Rifki adalah Tingkat Depresi Ringan D. PENGUJIAN WHITEBOX

a. Himpunan Keanggotaan

Tabel 3. Source Himpunan Keanggotaan

\begin{tabular}{|c|l|}
\hline Node & \multicolumn{1}{|c|}{ Source Code } \\
\hline 1 & Dim a, b, c As Double \\
\hline 2 & If My.Settings.if1r1 = "FKminimal" Then \\
\hline 3 & a = fkminimal.Text \\
\hline 4 & ElseIf My.Settings.if1r1 = "FKrendah" Then \\
\hline 5 & a = fkrendah.Text \\
\hline 6 & ElseIf My.Settings.if1r1 = "FKsedang" Then \\
\hline 7 & a = fksedang.Text \\
\hline 8 & ElseIf My.Settings.if1r1 = "FKberat" Then \\
\hline 9 & a = fkberat.Text \\
\hline 10 & End If \\
\hline 11 & If My.Settings.if2r1 = "FAminimal" Then \\
\hline 12 & b = faminimal.Text \\
\hline 13 & ElseIf My.Settings.if2r1 = "FArendah" Then \\
\hline 14 & b = farendah.Text \\
\hline 15 & ElseIf My.Settings.if2r1 = "FAsedang" Then \\
\hline 16 & b = fasedang.Text \\
\hline 17 & ElseIf My.Settings.if2r1 = "FAberat" Then \\
\hline 18 & b = faberat.Text \\
\hline 19 & End If \\
\hline 20 & If My.Settings.if3r1 = "FSminimal" Then \\
\hline 21 & c = fsminimal.Text \\
\hline 22 & ElseIf My.Settings.if3r1 = "FSrendah" Then \\
\hline 23 & c = fsrendah.Text \\
\hline 24 & ElseIf My.Settings.if3r1 = "FSsedang" Then \\
\hline 25 & c = fssedang.Text \\
\hline 26 & ElseIf My.Settings.if3r1 = "FSberat" Then \\
\hline 27 & c = fsberat.Text \\
\hline 28 & End If \\
\hline 29 & Dim vals As Double( $=\{$ Val(a), Val(b), Val(c) $\}$ \\
\hline 30 & Dim largest As Double = Double.MaxValue \\
\hline 31 & For Each element As Double In vals \\
\hline 32 & largest = Math.Min(largest, element $)$ \\
\hline 33 & a1.Text = largest \\
\hline 34 & Next \\
\hline
\end{tabular}

Flow Graph Himpunan Keanggotaan Algoritma Fuzzy Logic berdasarkan pseudocode di atas maka flow graph algoritma fuzzy logic adalah sebagai berikut:

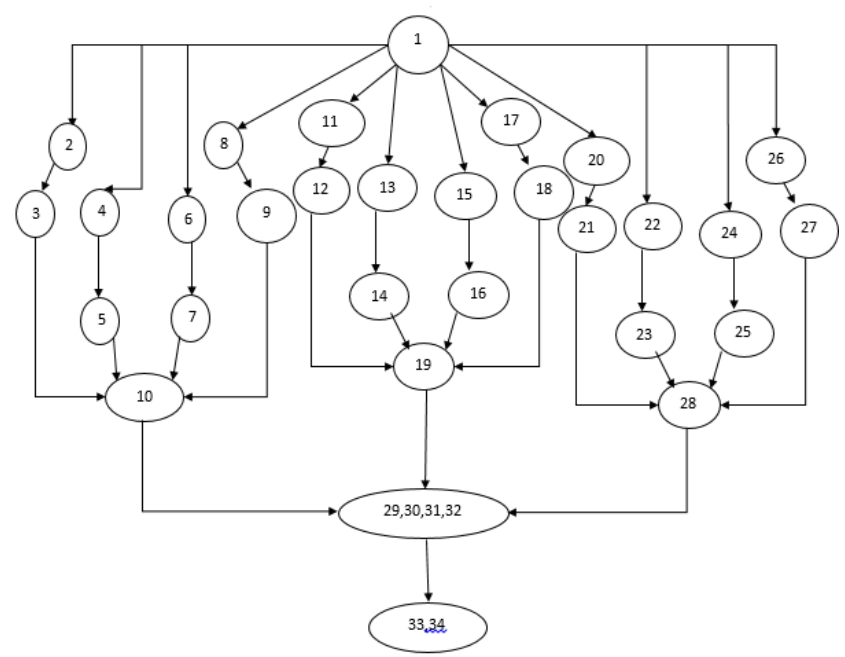

Gambar 10. Cyclomatic Complexity

Himpunan Keanggotaan dari gambar diatas dapat ditentukan Cyclomatic Complexity sebagai berikut :
$\mathrm{V}(\mathrm{G})=\mathrm{E}-\mathrm{N}+2$
$=40-30+2$
$=12$
$\mathrm{E}=$ Jumlah busur pada flow
graph yaitu 40
$\mathrm{N}=$ Jumlah simpul pada flow graph yaitu 30

\section{E. PERHITUNGAN FUZZY DAN BDI III}

Sistem penilaian pada aplikasi Sistem Pakar Diagnosa Tingkat Depresi Pada Mahasiswa Tingkat Akhir Menggunakan Metode Fuzzy Tsukamoto ini berdasarkan uji coba pada objek penelitian sebanyak 25 responden. Dari hasil uji coba diperoleh kesesuaian antara tingkat depresi BDI II dan Fuzzy Tsukamoto sebanyak 24 data. Dengan probabilitas kesesuaian tingkat depresi antara BDI dengan Fuzzy Tsukamoto adalah :

$$
\begin{aligned}
\text { Psesuai } & =\frac{\text { Data sesuai }}{25} \times 100 \% \\
& =\frac{24}{25} \times 100 \% \\
& =96 \%
\end{aligned}
$$

Dan probabilitas ketidak sesuaian tingkat depresi antara BDI dengan Fuzzy Tsukamoto adalah :

$$
\begin{aligned}
\text { Ptidaksesuai } & =\frac{\text { Data tidak sesuai }}{25} \times 100 \% \\
& =\frac{1}{25} \times 100 \% \\
& =4 \%
\end{aligned}
$$

Melihat nilai probabilitas yang mencapai kesesuaian data mencapai 96\%, menunjukkan bahwa sistem pakar ini sudah berfungsi dengan baik. Dengan demikian, diharapkan sistem pakar ini dapat membantu dalam mendiagnosa tingkat depresi pada mahasiswa tingkat akhir.

\section{A. KESIMPULAN}

\section{KESIMPULAN DAN SARAN}

Setelah melakukan serangkaian penelitian, maka pada bab ini akan menyimpulkan dari uraian penelitian pada bab sebelumnya. Kesimpulan yang diperoleh adalah sebagai berikut:

1. Telah berhasil dibuat sebuah sistem pakar untuk mendiagnosa depresi berbasis Desktop.

2. Dapat mengimplementasikan logika fuzzy kedalam sebuah sistem pakar/

3. Dengan hasil perbandingan keakuratan sebesar $96 \%$ aplikasi sistem pakar diagnose tingkat depresi pada mahasiswa tingkat akhir ini dapat membantu 
psikolog/konselor universitas dalam mendiagnosa tingkat depresi mahasiswa.

\section{B. SARAN}

Berdasarkan kesimpulan yang telah dikemukakan, dapat diajukan beberapa saran untuk pengembangan lebih lanjut, diantaranya :

1. Aplikasi ini dapat dikembangkan menjadi aplikasi berbasis web atau pun mobile.

2. Perlu ditambahkan fitur Autoupdateatau pembaruan otomatis agar aplikasi tetap up to date dari sisi bug, penambahan gejala, pengetahuan, dan lain-lainnya.

3. Sebaiknya sistem dikombinasikan dengan metode lain agar nilai keakuratannya semakin besar.

\section{DAFTAR PUSTAKA}

[1] Beck,A. T. (2006). Depression: Causes and Treatment. Philadelphia: University of Pennsylvania Press.

[2] Durkin, J. (1994). Expert Systems Design and Development. New Jersey: Prentice Hall International Inc.

[3] Dologite, D. G. 1993. Developing Knowledge-Based System Using VP-Expert. New York: Macmillan Publishing Company.

[4] Gonzalez, A. J dan Dankel D. D. 1993. The Engineering of Knowledge-based System. New Jersey: Prentice Hall inc.

[5] Hariyanto,A.D.(2010).Pravelensi Depresi dan Faktor yang Mempengaruhi Pada Mahasiswa Fakultas Kedokteran Universitas Katolik Indonesia Atma Jaya Angkatan 2007. Jakarta: Karya Tulis Ilmiah Kedokteran.

[6] Hawari, D. (2010), Psikopatologi Bunuh Diri. Jakarta Balai Penerbit FK UI

[7] National Institutes of Mental Health,(2012).Depression and College Students". United States: Departement Of Health And Human Services.

[8] Kusumadewi, Sri dan Purnomo, Hari., Aplikasi Logika Fuzzy Untuk Pendukung Keputusan, Graha Ilmu, Yogyakarta: 2010

[9] Kusrini. 2006. Sistem Pakar (Teori dan Aplikasi).

Yogyakarta: Andi Offset. 